\title{
Determination
}

\section{of quasi-filtration phase of consolidation based on experimental and theoretical course of the uniaxial deformation and distribution of pore pressure}

\author{
Bartłomiej Szczepan Olek, Henryk Woźniak \\ AGH University of Science and Technology, Faculty of Geology, Geophysics and Environment Protection, \\ Department of Hydrogeology and Engineering Geology; al. A. Mickiewicza 30, 30-059 Krakow, Poland; \\ e-mail:bartlomolek@gmail.com,hwozniak@geol.agh.edu.pl
}

\begin{abstract}
(C) 2016 Authors. This is an open access publication, which can be used, distributed and reproduced in any medium according to the Creative Commons CC-BY 4.0 License requiring that the original work has been properly cited.
\end{abstract}

Received: 30 March 2016; accepted: 6 December 2016

\begin{abstract}
In this work the consolidation characteristics of the experimental and theoretical process of consolidation was studied. The analyses were carried out on the basis of the axial soil deformation progress and the pore pressure dissipation. The applied methodology gives possibility for the simultaneous comparison of the experimental and theoretical consolidation data and verification of the validity of calculated values of coefficient of consolidation, estimated using different methods. The aim of this research was to put some light on the quasi-filtration phase of consolidation. The results of consolidation studies on five high quality paste samples prepared from Krakowiec clays showed that the quasi-filtration occurs only in specific stages of the whole process. The analysis of changes in coefficient of consolidation depending on the degree of consolidation, enables the separation of the region of quasi-fixed values of $c_{v}$, which corresponds to the quasi-filtration phase of consolidation.
\end{abstract}

Keywords: clays, consolidation, filtration, creep, coefficient of consolidation

\section{INTRODUCTION}

Consolidation tests enable the determination of consolidation parameters. The knowledge of these parameters is required for permeability assessment as well as forecasting settlement - in particular, for low-permeability, cohesive soils.

The primary problem in obtaining reliable results of consolidation testing is the adoption of an adequate theoretical solution and specification of a calculation model. The widely used Terzaghi's theory is severely limited and involves multiple simplifications (Crawford 1986, Duncan 1993, Sridharan
\& Prakash 1995a). Furthermore, the laboratory procedure and design of measurement instruments result in the creation of adverse distortion effects which, on the one hand, determine the nature of the resulting experimental curves and on the other, prevent the interpretation of the process as purely filtration-related. This means that they prevent full compliance of the experiment with theory. The difficulties in the isolation of a section compliant with the model are caused by several factors. The most common effects inducing the non-compliances are: initial compression and time-dependent effects typically assumed as creep. 


\section{PHENOMENOLOGICAL POSTULATES OF THE CONSOLIDATION PROCESS DESCRIPTION}

The current accomplishments in the phenomenological description of the consolidation process can be reduced to the following postulates:

- During the filtration phase, the soil structure deformation is limited by the filtration ability of the pore fluid.

- The filtration phase coexists with the rheological phase (viscosity effects) which clearly manifests in the later stages of the process, usually after reaching $50-60 \%$ consolidation progress.

- The rheological mechanism results in soil deformation which is related to the reorganization of the mineral skeleton structure. This mechanism describes the reaction of particles to one-dimensional loading and results from the friction on the contact surfaces of strain-bearing particles.

- The Poisson process occurs during one-directional consolidation (Joseph 2013, 2014a, 2014b) - particle movement during one-directional consolidation, approaching a set structure pseudo-flow state with random shearing deformations.

- In the case of low permeability soils, the stabilization of the dispersion of excessive pore pressure is observed before its complete dissipation. One explanation of this phenomenon can be given making a hypothesis for shrinking of water migration corridors resulting in the decrease of the hydraulic gradient below critical value.

- The soil considered to be compliant to Terzaghi's theory can only be viewed as such in individual one-dimensional consolidation process phases.

The purpose of this study is the comparison of the experimental course of consolidation with the theoretical solution and distinction of the quasi-filtration phase of the process as well as the verification of the reliability of the anticipated values of the coefficient of consolidation with the use of multiple consolidation testing interpretation techniques.

\section{METHODOLOGY}

The testing was performed using a Rowe \& Barden hydraulic consolidometer type EL25-0700 made by ELE International (Fig. 1). The most important feature of this system is the ability to control the conditions of drainage and the opportunity of measurement of pore water pressure. The consolidometer used in this study also allows for both vertical and radial flow tests for consolidation and direct permeability measurements. In addition, the hydraulic system provides precise control of the applied loads in a wide range. The consolidation cell is made of stainless steel and consists of three basic elements: the lower base, the central cell and the top cover. Lower base contains two ports that allow the measurement of pore pressure. The pore pressure was recorded centrally on the bottom surface of the sample at the impermeable base of the cell. Pressure systems equipped with sensors was connected to a data acquisition station. Before the test all the flexible leads are vented. The applied incremental loading (IL) system had increment paths of $100 \mathrm{kPa}$ and $200 \mathrm{kPa}$, with uniform stress distribution and single-side drainage conditions. A displacement sensor with the tolerance of $0.002 \mathrm{~mm}$ was used to measure the change in sample height $-\delta$.

The widespread use of the Rowe cell has also focused some disadvantages of the system. Khan \& Garga (1994) pointed out two general problems associated with use of diaphfragm loading system. The authors indicated the difficulties to assemble the diaphfragm loading system without entrapping air or water between the bellofram and the cell wall. Moreover, they stated that the force applied to the diaphragm is not fully transmitted to the sample, the discrepancies could reach 15-20\%.

Blewett et al. (2002) compiled disadvantages of the conventional Rowe cell with special focus to soil fabric disturbances as follows:

- the assembly of the bellofram on top of the sample can lead to soil fabric disturbance,

- difficulty of getting an initial level loading surface on the sample,

- lack of rigidity of the bellofram.

Other shortcomings are referenced to the relative stiffness of the flexible leads of the pressure system and specific deformation capacity of the stainless steel cell walls. 


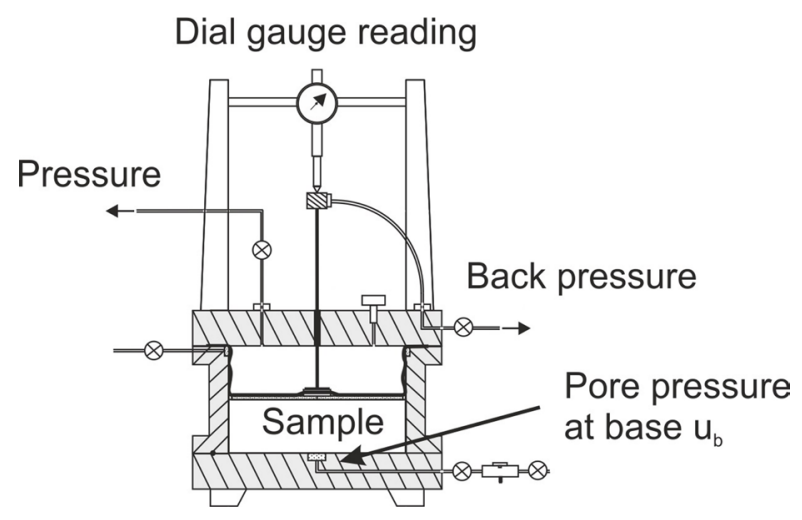

Fig. 1. Arrangement of Barden-Rowe cell

The analytical procedure (Sridharan et al. 1995b) was applied for the comparison of the experimental and theoretical process of consolidation as well as for the verification of the validity of anticipated values of coefficient of consolidation, estimated using different methods. The procedure assumes to use a single diagram with experimental values, represented by $\delta-t$ measurement coordinates in relation to model curves $\log _{10}\left(H^{2} / t_{\text {theor }}\right)$ - $U$ (Fig. 2), drawn based on the one-dimensional strain ODS or pore pressure dissipation PPD. By the collation of experimental $\log _{10}\left(H^{2} / t_{\text {exp }}\right)-U$ curves and model curves $\log _{10}\left(H^{2} / t_{\text {theor }}\right)-U$, established for the optional values of the coefficient of consolidation $c_{v(\mathrm{opt})}$ and correspondent time $t_{\text {theor }}$, the identification of distinct process stages is possible. Abbreviation $H$ denotes the sample height which corresponds to the length of the drainage path of a consolidating soil layer; $t_{\text {theor }}$ is the theoretical time calculated on the basis of optional value of coefficient of consolidation; $t_{\exp }$ is experimental time (time reading); $U$ is the degree of consolidation. Theoretical time can be calculated from the following equation:

$t_{\text {theor }}=\frac{T H^{2}}{c_{v(\text { opt })}}$

where, $T$ is the non-dimensional time factor. Note that, optional coefficient of consolidation $c_{v(\mathrm{opt})}$ used in equation (1) denotes whichever value of $c_{v}$ obtained by whichever method.

The presented methodology allows a simple way of determination of the filtration phase of consolidation by identifying two key points. The first is represented by the end of initial compression and the second by visible beginning of secondary compression in $\log _{10}\left(H^{2} / t\right)-U$ space (Fig. 3). Testing using an oedometer or consolidometer are bound by limitations, resulting in observed discrepancies with the applied Terzaghi's theory of consolidation. The soil considered to be compliant to Terzaghi's theory can only be viewed as such in the individual consolidation process phase. The generally accepted division recognises three phases in terms of strains. There is initial compression, primary compression and secondary compression. While the initial compression occurs immediately after the application of a load increment, the primary consolidation and the secondary compression are time-dependent.

The coefficient of consolidation $c_{v}$ used in the calculations was determined by semi-analytical curve matching procedures as well as analytical methods. Over the last 50 years, several arduous and time-consuming attempts were made to develop the appropriate methodology and interpretation standards for consolidation studies. The most elusive problem is still the estimation of real $c_{v}$ values. Methods of determining this parameter can be divided into three groups. The first applies to "curve matching", in which the measured consolidation settlement $\delta-t$ curve is compared to the theoretical progress of consolidation $U-T$ curve. In these procedures, the values of the $c_{y}$ are calculated based on the matching of a single experimental point to the related consolidation progress. For example, for the logarithm of time method (Casagrande \& Fadum 1940) we search for pairs: $\left(\delta_{50}, t_{50}\right)$ and $\left(U_{50}, T_{50}\right)$. Thus, the generalised formula for calculating the coefficient of consolidation can be written as:

$c_{v, \text { Casagrande }}=\frac{T_{50} H_{50}^{2}}{t_{50}}$

The second group is represented by analytical methods, which do not require the matching procedure in order to determine the consolidation characteristics and estimation of the coefficient of consolidation. The third are combined methods. During the preliminary work, tools were selected to determine the coefficient of consolidation from the experimental curve sections least affected by the impact of initial compression and rheological consolidation. The basic criterion for "matching" methods is assumed to be the compatibility of the test with the theoretical solution. 


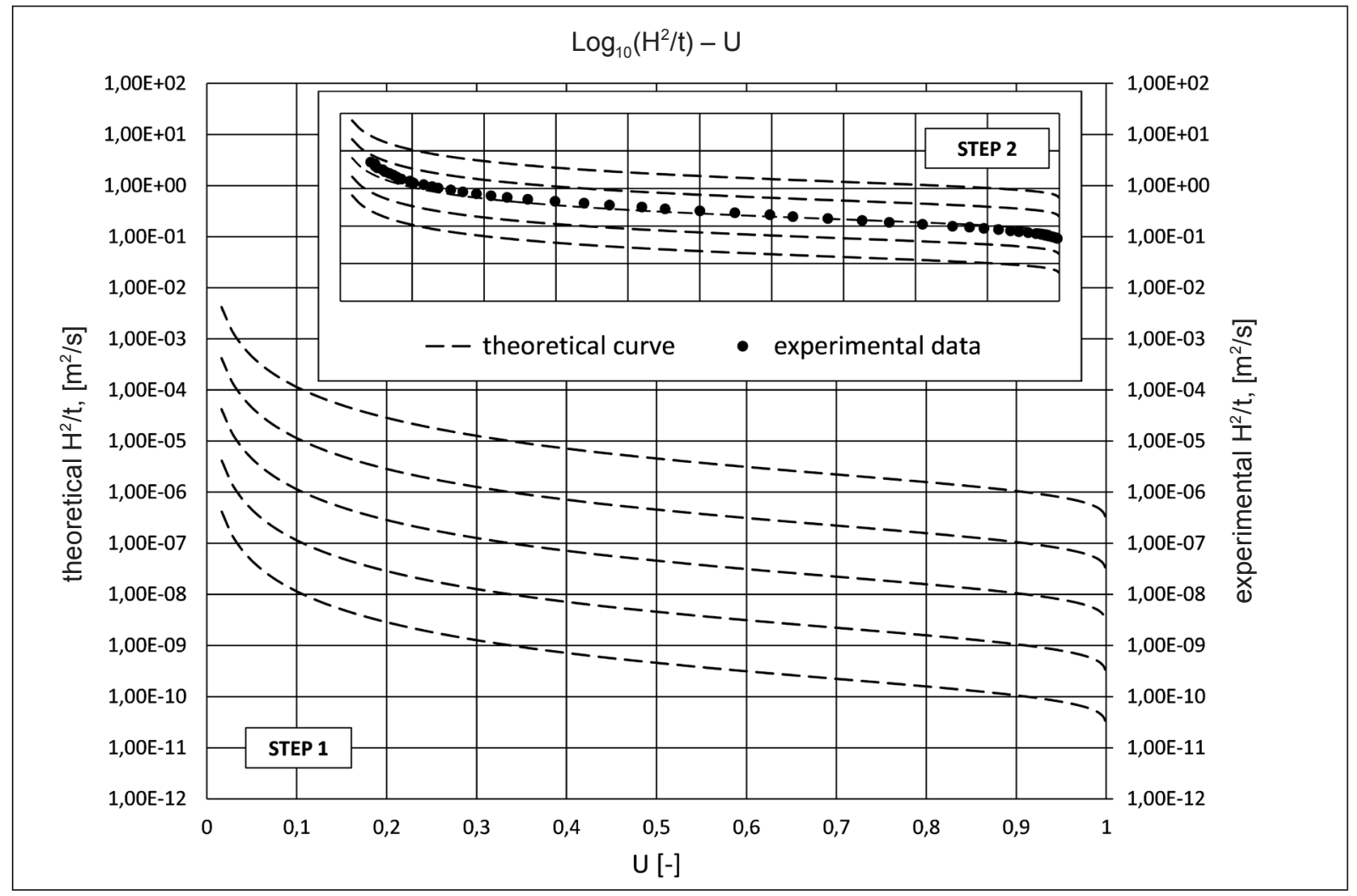

Fig. 2. Distribution of $\log _{10}\left(H^{2} / t_{\text {theor }}\right)-U$ curves with superimposed $\log _{10}\left(H^{2} / t_{\text {exp }}\right)-U$ curve

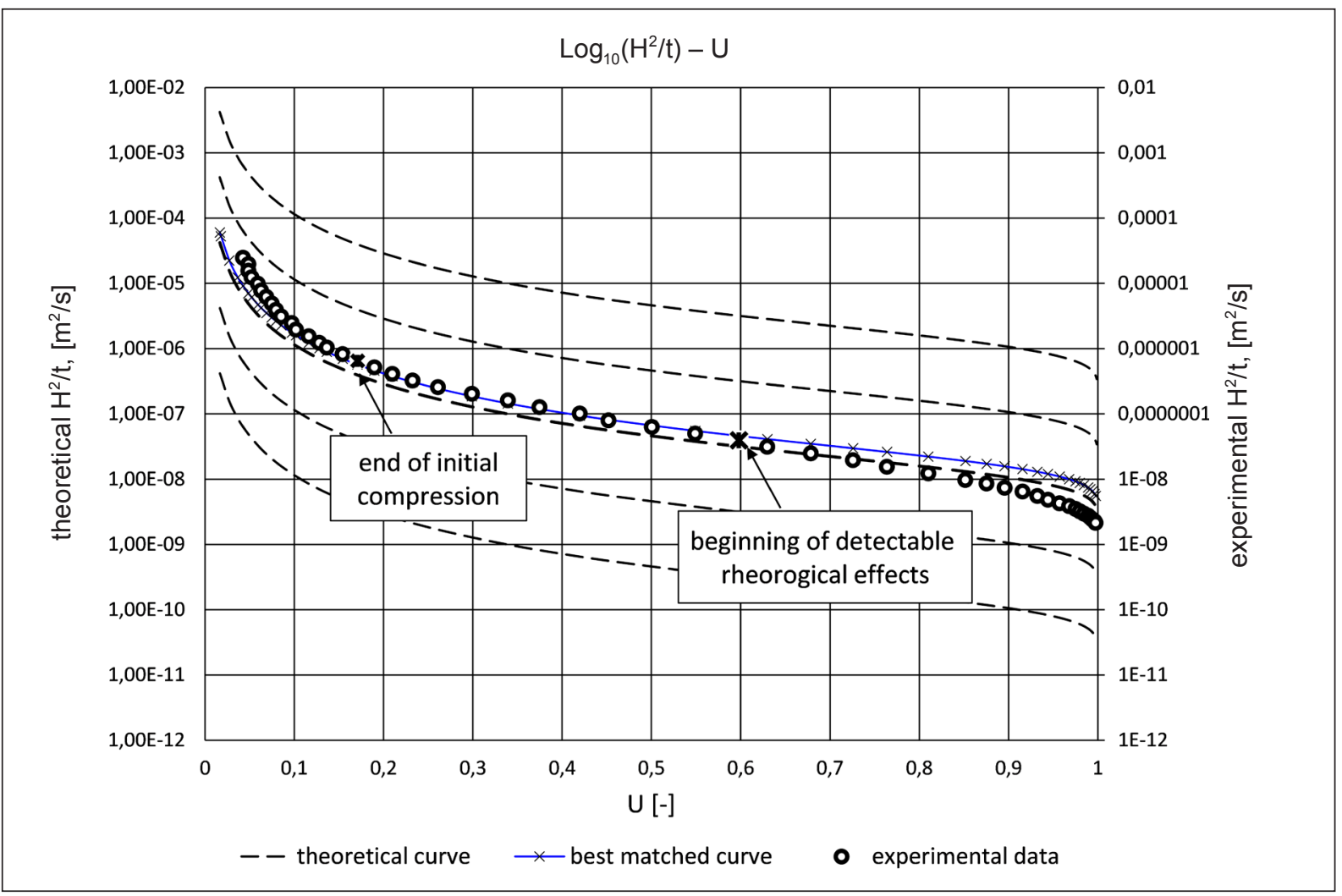

Fig. 3. Distribution of $\log _{10}\left(H^{2} / t_{\text {theor }}\right)-U$ curves with superimposed $\log _{10}\left(H^{2} / t_{\text {exp }}\right)-U$ curve and determination of key points for identification the end of initial compression and beginning of secondary compression 
The following methods for determining the coefficient of consolidation were applied using the aforementioned criterion in the analysis: logarithm of time CA (Casagrande \& Fadum 1940), inflection point IP (Mesri \& Feng 1999), logarithmic LL (Sridharan \& Prakash 1997), modified velocity $\left(\delta-\log \mathrm{d} \delta / \mathrm{d} t-V T_{1}, \delta-\mathrm{d} \delta / \mathrm{d} t-V T_{2}\right)($ Tewatia 1998, Tewatia et al. 2013, Olek et al. 2016). The verification tool for the calculated $c_{v}$ values was the approximation method in two variants: approximation course of strain (ACOS) and approximation course of pore pressure (ACOP) (Dobak \& Pająk 2012, Dobak \& Gaszyński 2014), whereby the course of the experiment is compared to the theoretical solution.

\section{APPROXIMATION METHOD}

Consolidation testing records changes in sample height $\delta$ as well as changes in the excessive pore pressure $u$ in relation to time $t$. For each reference point a corresponding experimental degree of consolidation $U$ (specifying the advancement of the process) is determined by the following relations:

$$
\begin{gathered}
U_{\mathrm{ODS}}=\frac{R_{0}-R_{i}}{R_{0}-R_{100}} \\
U_{\mathrm{PPD}}=\frac{u_{0}-u_{i}}{u_{0}-u_{100}}
\end{gathered}
$$

where $R_{0}$ is the initial reading from the displacement sensor under the analysed stress level; $R_{i}$ is the reading from the displacement sensor at the given time; $R_{100}$ is the final reading from the displacement sensor for the given stress; $u_{0}$ is the pore pressure value at the initial stage of consolidation; $u_{i}$ is the pore pressure value in the analysed time $t$; $u_{100}$ is the final pore pressure value. The approximation method involves selecting the model curve closest (best match) to the experimental course of the consolidation process. The comparison criterion proposed by the authors is the $d_{u}$ index:

$d_{U}=\frac{\sum \frac{\left|U_{\text {exp }, i}-U_{\text {theor }, i}\right|}{U_{\text {exp }, i}}}{n_{i}}$

$$
U_{\exp }=U_{\mathrm{ODS}} \vee U_{\mathrm{PPD}}
$$

where $n_{i}$ is the number of analysed measurement values $i, U_{\text {exp, } i}$ is the experimental level of consolidation referring to one-dimensional strain ODS or pore pressure dissipation PPD, $U_{\text {theor }}$ is the theoretical level of consolidation. In this method the analytical procedure is used to determine the theoretical course of the consolidation process in relation to the experimental records of actual time $t_{i}$ and the height of the testing sample $h_{i}$. Then, the theoretical time factor is determined:

$T_{i}=\frac{c_{v} t_{i}}{h_{i}^{2}}$

for several values of coefficient of consolidation $c_{v}$. On the basis of above notation, the theoretical time factor is determined and from standard relationship (Taylor 1948) the theoretical value of degree of consolidation $U_{\text {theor }}$ could be obtained. The procedure to compare the experimental and theoretical consolidation behaviour and determine through the $c_{v}$ is shown on Figure 4. Note that curves I to VII are model curves obtained application of different values of coefficient of consolidation. In this method, the best matched model curve is the one for which the $d_{u}$ index has the lowest values (Dobak \& Pająk 2012). Dobak \& Gaszyński (2014) provided an even better criterion for compatibility of theoretical and experimental characteristics by introducing a weighted average into consideration. The application of the weighted average enables a more accurate determination of the representation to measurement data in the conditions of shifting direction deformation or pore pressure dissipation:

$d_{U}=\frac{\sum \frac{\left|U_{\text {exp }, i}-U_{\text {theor }, i}\right|}{U_{\text {exp }, i}} \cdot w_{n, i}}{\sum w_{n, i}}$

$w_{n, i}=\frac{U_{\text {theor }, i}-U_{\text {theor }, i-1}}{2}+\frac{U_{\text {theor }, i+1}-U_{\text {theor }, i}}{2}$ 


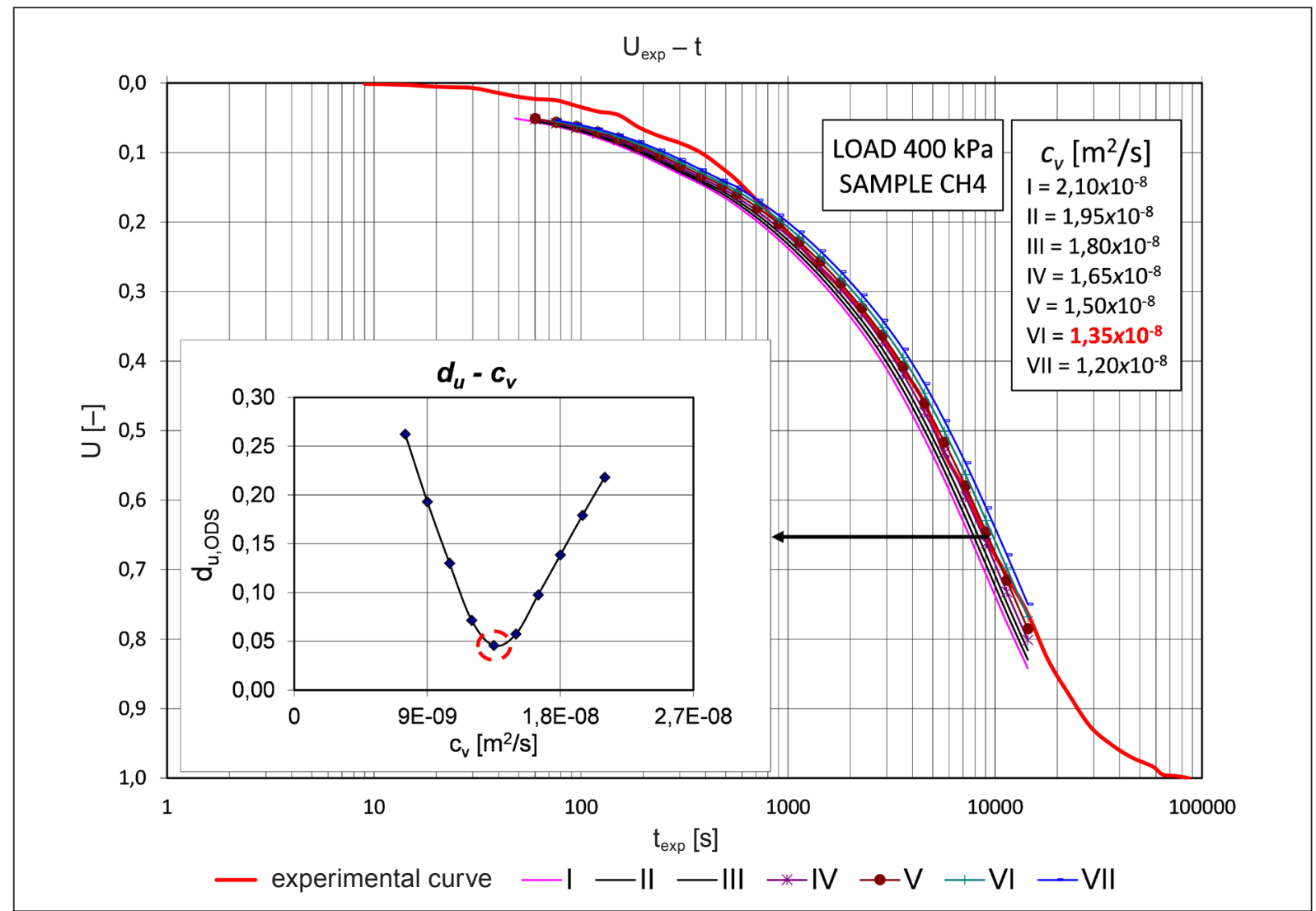

Fig. 4. Analysis for coefficient of consolidation by ACOS method - course of experimental consolidation relating to model curves and change of the $d_{u}$ indicator $v$ s the assumed values of $c_{v(o p t)}$

\section{RESEARCH MATERIAL}

The testing was performed on a sediment of clay suspension, based on Miocene Krakowiec clays from Chmielów (Podkarpackie province, Poland). These soils developed the form of grey clays, locally with a green or ash-grey tint. These clays, sometimes with sand interbeddings and inserts are a part of the complex of pre-Carpathian Sarmatian sink deposits.
The physical parameters and granulometric composition of the soil used to make the pastes are as follows:

- fraction content: clay - $48 \%$, silt - $38 \%$, sand $14 \%$;

- density of solid particles $\rho_{s}=2.72 \mathrm{~g} / \mathrm{cm}^{3}$, plastic limit $\mathrm{PL}=24.6 \%$, liquid limit $\mathrm{LL}=65.02 \%$.

The parameters of the Krakowiec clay soil paste prepared for testing are presented in Table 1.

Table 1. Changes in moisture and density of soil paste in the course of experiment.

\begin{tabular}{|c|c|c|c|c|c|}
\hline \multirow{2}{*}{ Sample No } & \multicolumn{2}{|c|}{ Introductory consolidation of soil paste } & \multicolumn{2}{c|}{ IL consolidation test } \\
\cline { 2 - 6 } & initial state & \multicolumn{2}{|c|}{ final state } & \multicolumn{2}{c|}{ the final state (after last loading step) } \\
\cline { 2 - 6 } & $\boldsymbol{w}$ & $\boldsymbol{w}$ & $\boldsymbol{\rho}$ & $\boldsymbol{w}$ & $\boldsymbol{\rho}$ \\
\cline { 2 - 6 } & {$[\%]$} & {$[\%]$} & {$\left[\mathrm{g} / \mathrm{cm}^{3}\right]$} & {$[\%]$} & {$\left[\mathrm{g} / \mathrm{cm}^{3}\right]$} \\
\hline $\mathrm{CH} 1$ & 65.02 & 43.0 & 1.62 & 30.0 & 1.74 \\
\hline $\mathrm{CH} 2$ & 65.01 & 43.0 & 1.60 & 30.0 & 1.78 \\
\hline $\mathrm{CH} 3$ & 65.02 & 43.1 & 1.62 & 34.0 & 1.75 \\
\hline $\mathrm{CH} 4$ & 65.02 & 46.0 & 1.61 & 30.0 & 1.73 \\
\hline $\mathrm{CH} 5$ & 65.00 & 42.0 & 1.58 & & \\
\hline
\end{tabular}


The pastes with plasticity approaching the liquid limit $\left(w_{n} \approx L L\right)$ were made from dried and mortar-ground soil mass combined with water to form a uniform texture. The next stage of sample preparation was preliminary, one-week consolidation in consolidation rings with the constant load of $100 \mathrm{kPa}$.

\section{RESULTS AND DISCUSSION}

In the present study, an experimental and theoretical behaviour of consolidation is compared to determine the quasi-filtration phase of this process based on matching procedure. Filtration consolidation is defined as time-dependent compression resulting from water pressure dissipation in the pores as a reaction to the application of stress. The compared theoretical and experimental $\log _{10}\left(H^{2} / t\right)$ curves in the same scale enable the determination of the scope of impact of initial compression and rheological effects in individual process stages.

Results of consolidometric tests conducted on five high quality paste samples, show that the quasi filtration phase occurs only in specific stages of consolidation process. In the early stage, under the first load increment the effect of initial compression is large and easy to identify. This regularity was observed in all analysed samples. For the example given in Figure 5 the end of the region influenced by initial compression occurs after $27 \%$ progress of consolidation. It is due to rearranging structure of soil induced by applied load and expulsion of air from the pore space. Effects of initial compression are significantly lower during the next load increments, in which the soil structure exhibits a more stable state. At this state between solid particles are formed privileged flow corridors. In this work only the second load stage, i.e. $400 \mathrm{kPa}$ was interpreted.

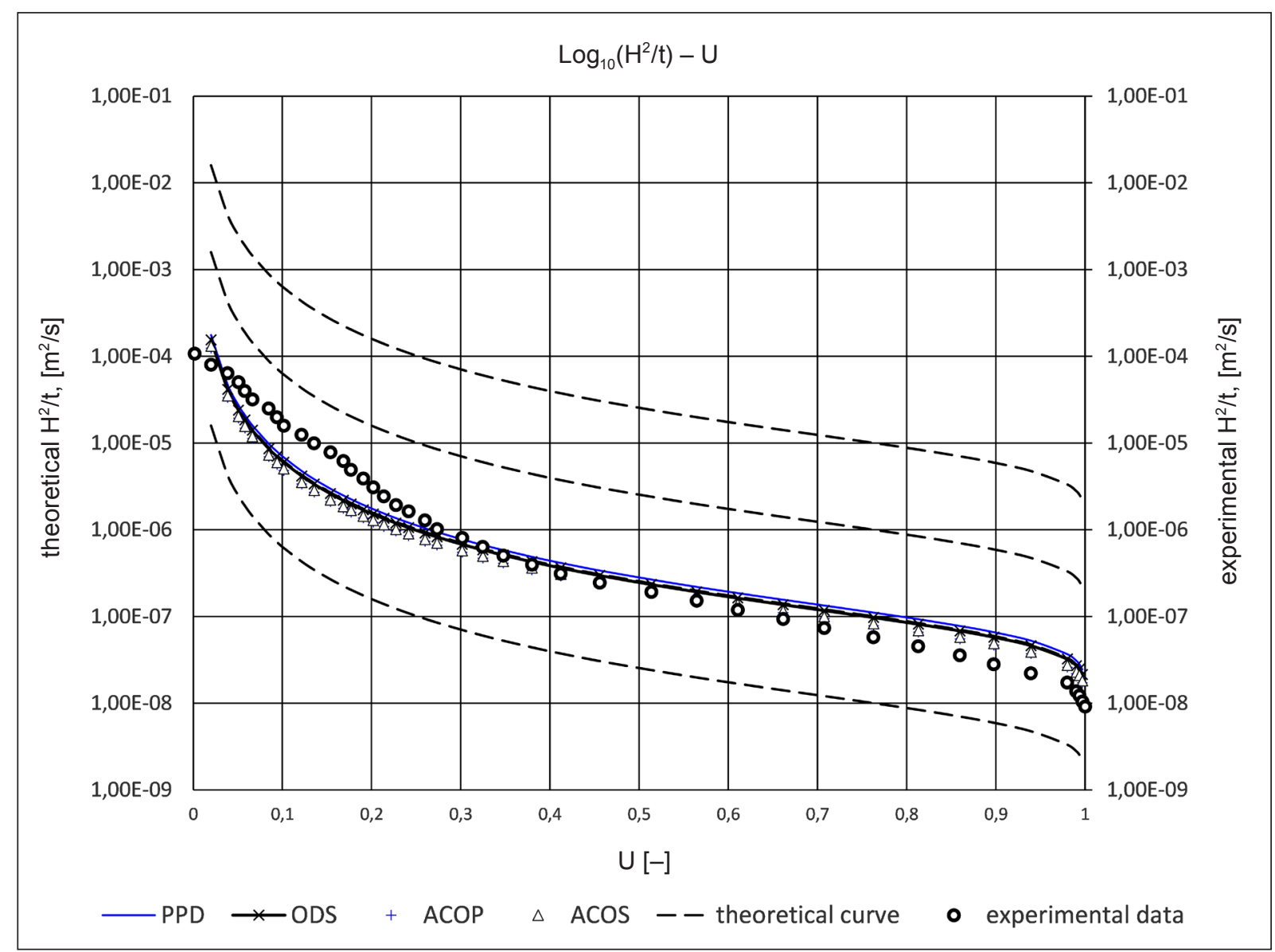

Fig. 5. Effect of large initial compression and secondary compression on sample CH4 under first load stage of $200 \mathrm{kPa}$ 
Taking into consideration this statement for the next load stage after application of model curves and found the two points which limit the quasi-filtration phase, it is possible to establish the range of the prevalence of compliance with the accepted theory. This enables the determination of a section closest to the theoretical solution. In other words, the determination of points related to the end of initial compression and the start of secondary compression on the curve shows the area of quasi-filtration behaviours. Figure 6 shows distribution of $\log _{10}\left(H^{2} / t_{\text {theor }}\right)$ - $U$ curves for different $c_{v}$ values, calculated from various methods. Common curve-fitting methods produce different coefficient of consolidation values and usually fail to adequately evaluate reasonable $c_{v}$ values.

For the given example the best compliance between the experimental course of consolidation and theoretical distribution was obtained when applying the values of coefficient of consolidation from approximation course of strain (ACOS), one-dimensional strain (ODS), $\delta-\log \mathrm{d} \delta / \mathrm{d} t-V T_{1}$ and inflection point (IP) methods. The $c_{v}$ values obtained using the nine different interpretation methods for sample $\mathrm{CH} 4$ are shown in Table 2.

The effect of secondary compression was also observerd. For all data sets, the visible beginning of secondary compression was observed for different advancement of the process. For sample $\mathrm{CH} 1$ the experimental curve is in agreement with Terzaghi's theory of consolidation only up to $U$ $=0.6$ (Fig. 6). This draws attention to the significant effect of amount of secondary compression during consolidation. As stated earlier various methods produce different coefficient of consolidation values. The $\log _{10}\left(H^{2} / t\right)-U$ approach provides the opportunity to choose the best-fit value of the coefficient of consolidation. Figure 7 shows an example of the experimental course of consolidation $\log _{10}\left(H^{2} / t_{\text {exp }}\right)$ - $U$ curve collated with model diagrams $\log _{10}\left(H^{2} / t_{\text {theor }}\right)-U$, calculated for the selected optional values of the coefficient of consolidation. The best conformity was obtained when applying the value of $c_{v}$ from approximation course of strain method.

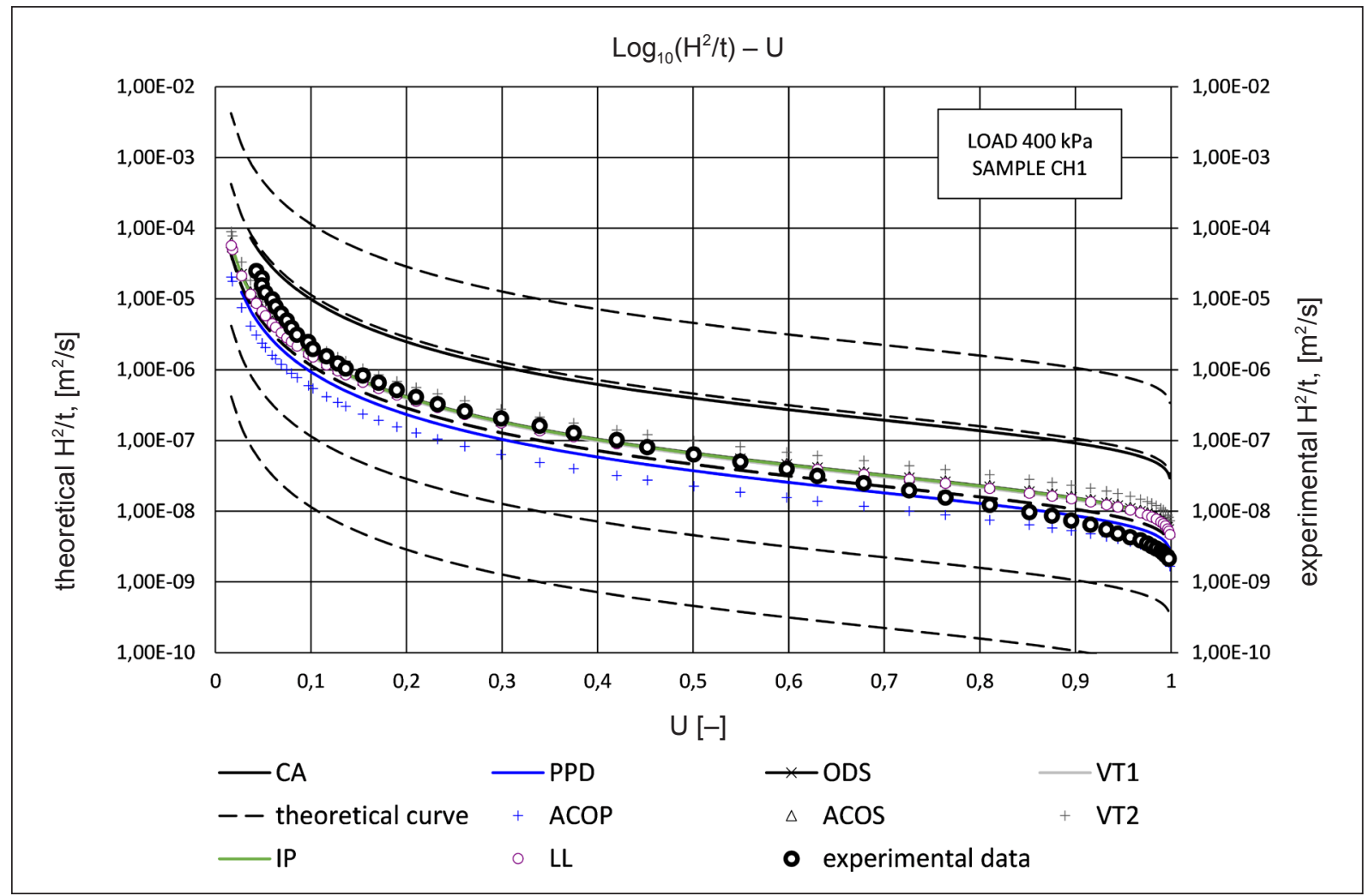

Fig. 6. Distribution of $\log _{10}\left(H^{2} / t_{\text {theor }}\right)-U$ curves for different $c_{v}$ values, calculated from logarithm of time CA, pore pressure dissipation (PPD), one-dimensional strain (ODS), $\delta-\log d \delta / d t-V T_{1}, \delta-d \delta / d t-V T_{2}$, approximation course of pore pressure (ACOP), approximation course of strain (ACOS), inflection point (IP), $\log \delta-\log t(L L)$ 
Table 2. Comparison of the $c_{v}\left[\mathrm{~m}^{2} / \mathrm{s}\right]$ values obtained using nine interpretation methods for pressure range 200-400 $\mathrm{kPa}$

\begin{tabular}{|c|c|c|c|c|c|c|c|c|c|c|}
\hline \multirow{2}{*}{ Sample } & \multirow{2}{*}{$\begin{array}{c}\text { Pressure } \\
\text { range } \\
{[\mathrm{kPa}]}\end{array}$} & \multicolumn{9}{|c|}{ Method } \\
\hline & & CA & PPD & ODS & VT1 & VT2 & ACOS & ACOP & IP & $\mathbf{L L}$ \\
\hline $\mathrm{CH} 1$ & $200-400$ & $1.36 \cdot 10^{-8}$ & $7.86 \cdot 10^{-9}$ & $1.30 \cdot 10^{-8}$ & $1.23 \cdot 10^{-8}$ & $1.61 \cdot 10^{-8}$ & $1.35 \cdot 10^{-8}$ & $4.40 \cdot 10^{-9}$ & $1.29 \cdot 10^{-8}$ & $1.24 \cdot 10^{-8}$ \\
\hline
\end{tabular}

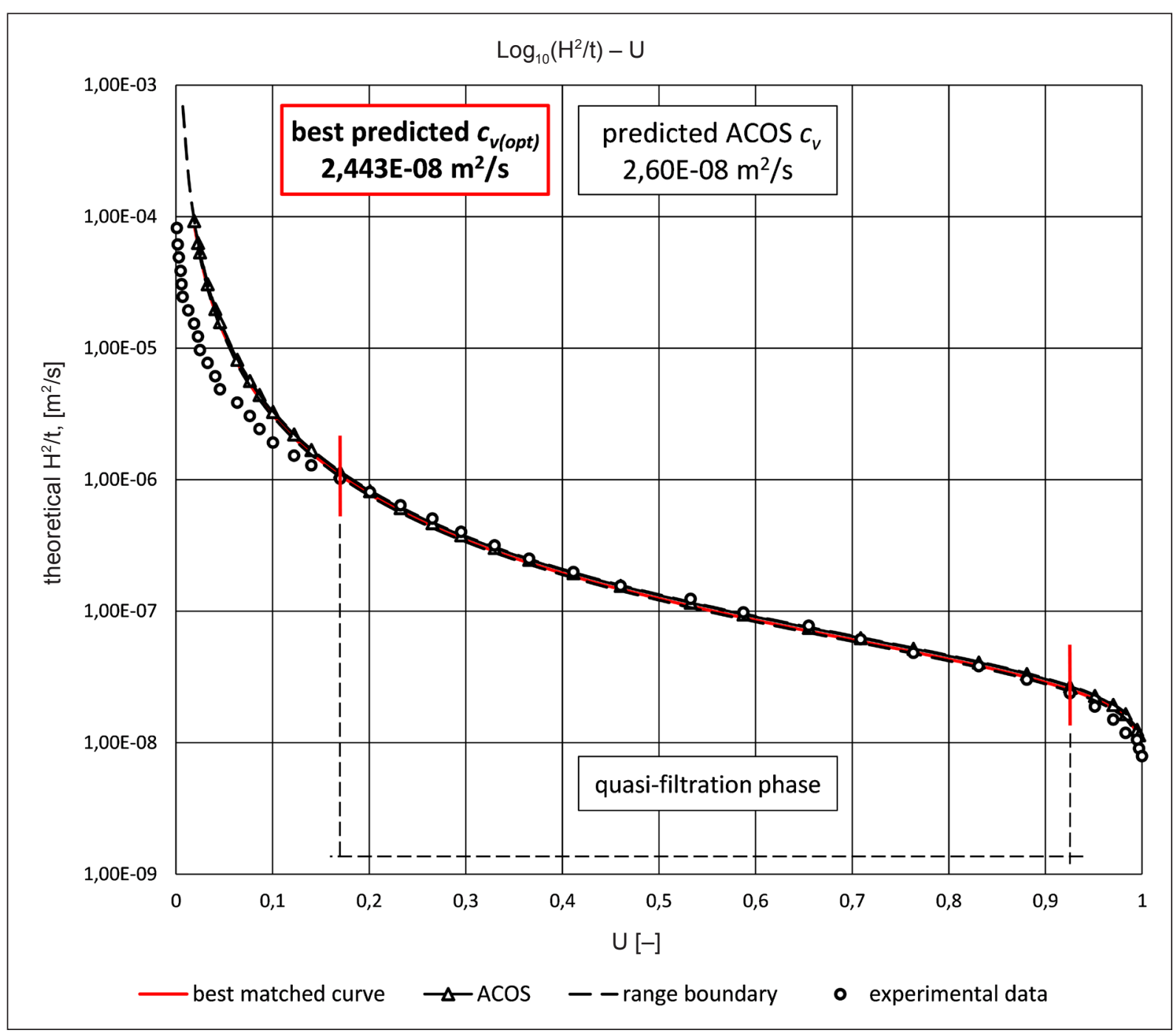

Fig. 7. Comparison between experimental and theoretical results using best predicted value of $c_{v(\text { opt })}$ and value calculated from approximation course of strain (ACOS) method for $\mathrm{CH} 4$ sample

The quasi-filtration phase, in the theoretical aspect should be characterised by semi-established $c_{v}$ values. An effective method of obtaining the quasi-establishment criterion is the drawing of the $\log c_{v}-U$ diagrams with the geometrical average of $c_{v}$ marked for the selected range. These parameters were obtained based on two solutions for the $U-T$ relationship - rectangular and parabolic. Calculated percentage of test advancement expressed by the degree of consolidation usually differs, taking into account changes in deformation progress and pore pressure dissipation. Most of the fine-grained soils exhibit a predominant consolidation ruling factor: creeping of soil skeleton or pore pressure dissipation. Determination of the coefficient of consolidation on the 
basis of one-dimensional strain analysis and pore pressure measurements in relation to the adopted theory should be the same. In practice there have been discrepancies in obtaining values of this parameter and in observed settlement and dissipation curves. Dobak \& Gaszyński (2014) distinguished two possible cases of discrepancies:

1) delays in pore pressure dissipation progress occur, in relation to deformation progress.

2) facilitation of pore pressure dissipation.

The $\log c_{v}-U$ curves (Fig. 8) illustrate the coexistence of three ranges of the coefficient of consolidation values for the entire scope of the level of consolidation. In the initial stage of the process $U \leq 0.25$, the coefficient of consolidation $c_{v}$ presents the highest values which are lowered with the increase of $U$ and stabilise at a quasi-linear form. The coefficient of consolidation always assumes lower values in the later stages of the consolidation process, depending on the impact of rheological mechanisms. The assumed rectangular distribution shows the quasi-established section for the coefficient of consolidation obtained based on the one-dimensional strain. The parabolic distribution should be applied to pore pressure dissipation.

The main advantage of this approach is the ability to direct evaluation of experimental data obtained by the convergence criterion of the theoretical condition. This condition is fulfilled in the case of determining the coefficient of consolidation for the quasi-filtration part of the consolidation. The presented approach could be applied for all fine-grained soils, even soils with high organic matter content.

\section{CONCLUSIONS}

1. The obtained $\delta-t$ consolidation curves are encumbered with errors caused by the initial compression and rheological consolidation effects. The distinction of the area with quasi-filtration behaviour on the curve is possible with the application of the Sridharan et al. (1995a) proposal which involves the comparison of the theoretical and the experimental course of the process.

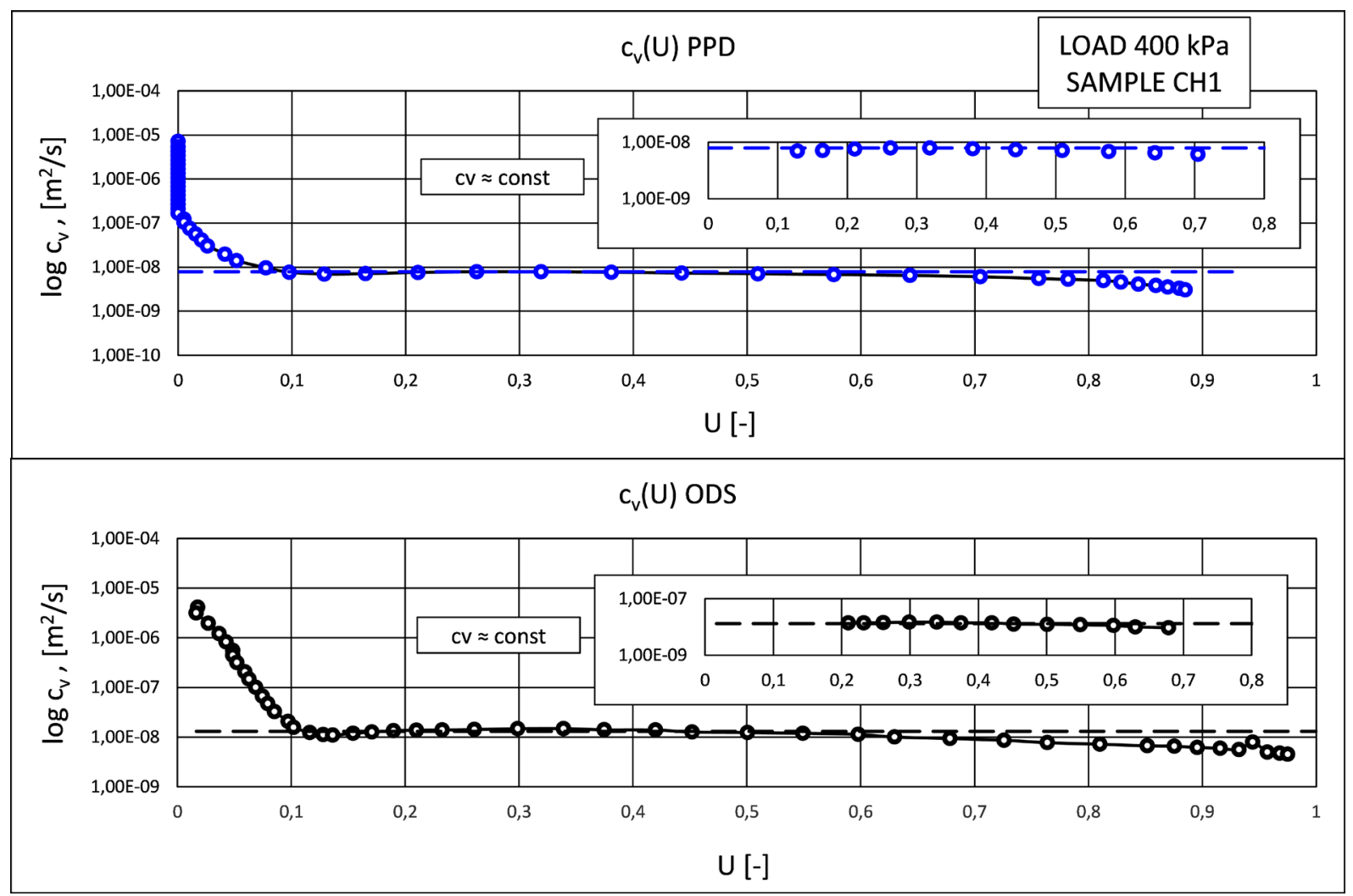

Fig. 8. Relation between coefficient of consolidation $c_{v}$ and degree of consolidation $U$ according to and pore pressure dissipation $(P P D)$ for parabolic distribution and one-dimensional strain (ODS) for rectangular distribution with visible quasi-constant curve portions for $\mathrm{CH} 1$ sample 
2. The procedure was verified using the approximation method, based on the studies completed with clay pastes. The values of the coefficient of consolidation determined with this method can be assumed to be actual values. The comparison yields a high degree of conformity, especially for the second load increment $(400 \mathrm{kPa})$.

3. The coefficient of consolidation determined based on the matching procedures is highly variable, due to the assumption of different reference points on the experimental curve. Based on the results of the tests, it can be said that the coefficient of consolidation values determined using the approximation course of strain (ACOP) and one-dimensional strain procedures are in the best agreement with theoretical solution.

4. Terzaghi's consolidation theory does not take into account the initial and rheological subsidence. It is recommended to remove affected areas before the interpretation of the test results.

5. The analysis of the changes in the coefficient of consolidation depending on the progress of consolidation showed the presence of a region with semi-established $c_{v}$ values. In the analysis based on the course of one-dimensional strain, the section is visible upon the application of rectangular distribution and for the course of pore pressure dissipation - parabolic distribution.

This paper was written based on the research made by Barttomiej Szczepan Olek to prepare his Ph.D. thesis.

Additionally, the first author thanks Mr. F.C. Sosa and Mr. Đúc Bùi of the Suranaree University of Technology for acquiring copies of papers as needed and Prof. P. Dobak of the University of Warsaw for extensive comments on the discussed approaches. The authors would like to thank the reviewers for their comments and suggestions that help improve the manuscript. The research was carried out under the Project N N525 254740 of the Polish National Centre of Science.

\section{REFERENCES}

Blewett J., McCarter W.J., Chrisp T.M. \& Starrs G., 2002. An automated and improved laboratory consolidation system. Canadian Geotechnical Journal, 39, 738-743.
Casagrande A. \& Fadum R.E., 1940. Notes on soil testing for engineering purposes. Harvard Soil Mechanics, 8, Harvard University, Graduate School of Engineering, Cambridge, Mass.

Crawford C.B., 1986. State of the art: Evaluation and interpretation of soil consolidation tests. [in:] Yong R.N., Townsend F.C., Consolidation of Soils: Testing and Evaluation, ASTM STP 892, ASTM International, 71-103.

Dobak P., Gaszyński J., 2014. Aspects of permeability and rheology in uniaxial consolidation, considering analysis of soil deformation progress and pore pressure dissipation. Architecture Civil Engineering Environment, 7, 4, 54-55.

Dobak P. \& Pająk R., 2012. Wpływ metod interpretacji badań konsolidacyjnych typu IL na zmienność oznaczeń przepuszczalności iłów krakowieckich. Biuletyn Państwowego Instytutu Geologicznego, 452, 217-224.

Duncan J.M., 1993. Limitations of conventional analysis of consolidation settlement. Journal of Geotechnical Engineering, 119, 9, 1333-1359.

Joseph P.G., 2013. Physical basis and validation of a constitutive model for soil shear derived from micro-structural changes. International Journal of Geomechanics, 13, 4, 365-383.

Joseph P.G., 2014a. Generalized dynamical systems based of on dynamical systems theory. Geotechnical Research, 1, $1,32-42$.

Joseph P.G., 2014b. Viscosity and secondary consolidation in one-dimensional loading. Geotechnical Research, 1, 3, 90-98.

Khan M.A. \& Garga V.K., 1994. A simple design for hydraulic consolidometer and volume gauge. Canadian Geotechnical Journal, 31, 769-772.

Mesri G. \& Feng T.W., 1999. Coefficient of consolidation by the inflection point method. Journal of Geotechnical and Geoenvironmental Engineering, 125, 8, 716-718.

Olek B.S., Woźniak H. \& Borecka A., 2016. Evaluation of consolidation results by the settlement rate approach. Electronic Journal of Geotechnical Engineering, 21, 7, 1583-1595.

Sridharan A. \& Prakash K. 1995a. Critical appraisal of laboratory determination of cv. [in:] Yoshikuni H. \& Kusakabe O. (eds.), Compression and consolidation of clayey soils Proceedings of the International Symposium on Compression and Consolidation of Clayey Soils, IS-Hiroshima '95, Japan, 10-12 May 1995, A.A. Balkema, Rotterdam, 567-572.

Sridharan A., Prakash K. \& Asha S.R., 1995b. Consolidation Behaviour of Soils. Geotechnical Testing Journal, 18, 1, 58-68.

Sridharan A. \& Prakash K., 1997. The $\log \delta$-logt method for the determination of coefficient of consolidation. Geotechnical Engineering, 125, 27-32.

Taylor D.W., 1948. Fundamentals of Soil Mechanics. John Wiley, New York.

Tewatia S.K., 1998. Evaluation of true $c_{v}$, instantaneous $c_{v}$ and isolation of secondary consolidation. Geotechnical Testing Journal, 21, 2, 102-108.

Tewatia S.K., Bose P.R. \& Sridharan A., 2013. Fastest Rapid Loading Methods of Vertical and Radial Consolidations. International Journal of Geomechanics, 13, 4, 332-339. 